May - 2021

\title{
Book Review: Learning Online-The Student Experience
}

\author{
Author: George Veletsianos (Baltimore: Johns Hopkins University Press, 2020, 174 pages) \\ Reviewed by: Özlem Oktay and Fırat Sösuncu, Anadolu University
}

Online learning is widely used at the global level and thousands of students are experiencing online learning. Online learners demonstrate demographic diversity. Therefore, the experiences of online learners also differ. Not knowing the difficulties experienced by online learners is an obstacle to designing effective courses, making necessary decisions, and acting with the feeling of empathy. In order to overcome this obstacle, it is necessary to have detailed information about the experiences of learners in online learning. Veletsianos acted with this idea, focusing on the experiences of online students, and analyzing the situation, presenting a true or composite story of an online student which was firstly gathered from his own research and experience, and occasionally from other reports. Thus, he aimed to provide a perspective to online learning, by looking through a different lens. He thinks that his perspective will help online instructors, researchers, administrators, instructional designers, teaching and learning center managers, policy makers, entrepreneurs, technology developers and higher education consultants to create a future that will meet the needs based on students' experiences.

Learning Online-The Student Experience, created with this in mind, consists of 17 chapters. In these chapters, the learner is defined in different ways: comparing face-to-face learning with online learning, fully motivated, deregistering, using a family computer, having the necessary literacy, watching videos alone, showing emotion, listening, cheating, taught by the internet robot, taking notes, using social networks, independent, using the advantage of openness in MOOCs, using the advantage of flexible learning and the learner of the future.

In Chapter 1, it is stated that modality should not be a barometer in evaluating quality in online and face-to-face learning and comparing face-to-face learning with online learning may cause misleading results. The reason for this is the differences in instructional design and differences in the situation of learners. In measuring the goodness of an online course, emphasis is placed on the degree of design and meeting the learner needs. In Chapter 2, it is stated that non-traditional students are composed of a large group of individuals who follow online learning opportunities, although there is an increase on a global scale, this is not the same in every country, and the majority of the group that feeds the increase trend is employees or adults. In Chapter 3, the reasons for the emergence of completely interested and highly motivated learners are emphasized, and it is stated that learners tend towards online learning due to internal and external factors. Attention is drawn to factors such as autonomy, flexibility, accessibility, financial concerns and belonging.

Chapter 4 explains the reasons for the learner's tendency to start online learning or quit online learning, as a complex problem consisting of the learner, curriculum, and environmental factors. It is stated that learning-oriented and innovative strategies should be developed with an ecological approach towards the solution. In Chapter 5, it is mentioned that the social justice orientation requires defining and 
removing obstacles based on the lack of access alone in achieving success in online learning. Chapter 6 describes 21st century skills, digital literacy, information literacy and participation literacy. Emphasis is placed on the necessity of participation literacy in online learning. It is pointed out that some learners may already exhibit participation literacy, while some learners may need support.

Chapter 7 focuses on learner isolation and loneliness. The importance of creating an online learning community is emphasized and learn how to use social media in order to provide social learning, cooperation and interaction easily. It is pointed out that there is a need for new pedagogical approaches that are appropriate for the digital age and emphasize connectivity. Chapter 8 articulates online learning as an emotional experience. It is explained that accepting online learning as an emotional experience may contribute to strengthening learner-teacher relationships and improving the quality of emotional relationships and education programs. Chapter 9 focuses on what is called a listener learner who does not participate in online learning. Implementation communities, community environment issues and reasons for lack of learner participation are addressed.

In Chapter 10, the subject of fraud in the academic environment is discussed with the title of cheating learner. It is pointed out that the methods developed to prevent this should be made not to wear down the sense of trust in the learner-teacher relationship. Chapter 11 deals with the learner taught by the internet robot, which can be valuable in terms of allowing us to think and develop new pedagogies, and the reader is encouraged to think about it with the help of questions. Chapter 12 details the topic of note taking learner, and it is stated that trainers and digital learning platforms can support the efforts of learners with applications that facilitate notetaking. In addition, emphasis is placed on collaborative notetaking, which can be effective in creating learning communities. In Chapter 13, the benefits of using social media in online learning for the learner are discussed, and the compatibility of social media technologies with progressive pedagogical approaches that value social interaction and participation is emphasized. Veletsianos argue that social media can be used as part of an effective tool set in online learning designs.

Chapter 14 focuses on learner autonomy, and self-directed learning skills are defined as a central component of online learning. Online learners are described as self-governing, autonomous and knowledgeable individuals. In addition, it is expressed that institutions should support and encourage learners to develop these features. In Chapter 15, the structure, advantages and disadvantages of MOOCs are demonstrated with examples from related research. Chapter 16 focusses on the flexibility of online learning that enables learners to balance multiple responsibilities. The chapter emphasizes that institutions should follow new policies and approaches to ensure and develop flexibility. In the last chapter, future trends in online learning are explained under the title of 'The Learner of the Future', and weaves of plausible stories around artificial intelligence, virtual and augmented reality, and highresolution simulations within a coherent learning ecosystem. However, it is stated that these trends should not be accepted blindly, and the underlying reasons should be investigated. In addition, the issue of focusing on macro-scale studies rather than micro-scale studies in research on online learning is emphasized.

With Learning Online-The Student Experience, Veletsianos sees individuals from different backgrounds as the target audience and points out that, for each target audience, there are lessons they can learn from the book. It aims to provide readers with introductory information about online learning and presents an experiential picture about it, as they are interested in online learning or are thinking about becoming an online learner. The author's suggestion for those who intend to offer an online 
program or improve their online education is to read the stories of the learners again and to answer some questions based on these stories.

These questions are as follows (pp. 166):

- Who are the students in the proposed online program?

- What do they need and why?

- Who has decided that an online degree or course is required and what are their motivations?

- Have students been consulted in the development of this program?

By answering these questions and keeping in mind that our target audience is not only learning but having other responsibilities and problems in life, it is necessary to think about providing learning and planning curriculum and designs accordingly.

As a result, Learning Online-The Student Experience reveals a different structure compared to its peers with the student experiences in each chapter, and presents the online learning experiences in a concrete way. In this context, it can be said that the book will benefit a wide spectrum ranging from the author's target audience to students, educators, designers, curriculum creators, education planners, and education managers.

Athabasca

University 